\title{
Early Coaching to Increase Water Intake in CKD
}

\author{
Mariia D. Ivanova $^{\text {a }}$ Anatoliy I. Gozhenko $^{\text {b }}$ Tommy Crestanello $^{c}$ \\ Dmytro D. Ivanov ${ }^{\mathrm{c}}$ \\ aMilano-Bicocca University, Milan, Italy; bUkrainian Scientific Research Institute of Transport, Odesa, Ukraine; \\ cShupyk National Medical Academy of Postgraduate Education, Kiev, Ukraine
}

\section{Keywords \\ Chronic kidney disease - Early coaching to increase water intake in chronic kidney disease - Estimated glomerular filtration rate $\cdot$ Renal functional reserve $\cdot$ Hydration}

\begin{abstract}
Introduction: In observational studies, increased water intake improves kidney function but not in adults with CKD stage 3 and more. CKD WIT trial has shown a nonsignificant gradual decline in kidney function after 1 year of coaching to increase water intake (CIWI) [1]. We propose that CIWI may benefit in CKD stage 1-2 (G1 and G2) and depends on functional renal functional reserve (RFR) $[2,3]$. Objective: Parallel-group randomized trial was aimed to determinate the effectiveness of CIWI dependence of estimated glomerular filtration rate (eGFR) stage and RFR in adults with CKD 1-2 stages. Methods: CKD WIT trial was taken as the basis for prospective multicenter randomized trial named "Early Coaching to Increase Water Intake in CKD (ECIWIC)." The primary outcome was the change in kidney function by eGFR from baseline to 12 months. Secondary outcomes included 1-year change in urine albumin/Cr ratio, and patient-reported overall quality of health $(\mathrm{QH})$ ranged from 0 (worst possible) to 10 (best possible). CIWI aimed to have the diuresis being 1.7-2 L. There were 4 groups with nondiet sodium restriction which consisted of 31 patients each: 2 groups with CKD G1 and CKD G2, undergoing CIWI and 2 others with CKD G1 and CKD G2 without CIWI (Fig. 1a). Overall checks were
\end{abstract}

karger@karger.com www.karger.com/anm Karger $\stackrel{\text { ' }}{5}$ BOPEN ACCESS
(C) 2021 The Author(s)

Published by S. Karger AG, Basel

This article is licensed under the Creative Commons AttributionNonCommercial-NoDerivatives 4.0 International License (CC BYNC-ND) (http://www.karger.com/Services/OpenAccessLicense) Usage and distribution for commercial purposes as well as any distribution of modified material requires written permission. made at 0,6 , and 12 months. RFR evaluation was performed using $0.45 \%$ sodium chloride oral solution. Results: Of our randomized 124 patients (mean age 53.2 years; men 83 [67\%], 0 died), mean change in 24-h urine volume was $0.6 \mathrm{~L}$ per day in G1 with CIWI group and $0.5 \mathrm{~L}$ in G2. No statistically significant data on eGFR depending CIWI were obtained (Fig. 1b). However, the trend suggests that CIWI improves eGFR in CKD G1 (from 95 to $96 \mathrm{~mL} / \mathrm{min} / 1.73 \mathrm{~m}^{2}$ ) and preserves eGFR decline in CKD G2 (78-78). The QH values were also preserved (from 7 to 7 in G1 and G2 groups). Although coaching to maintain the same water intake did not preserve physiological and pathological eGFR decreasing in CKD G1-2 (G1 from 96 to $93, \mathrm{G} 2$ from 76 to $73 ; t=0.6, p=0.29$, and $p \leq 0.05$ in all groups) and the $\mathrm{QH}$ was declined (from 7 to 6 in both groups). An individual analysis of the RFR has shown that patients with RFR more than 50\% (G1 19 patients, $61 \%$, and G2 13 patients, $42 \%$ ) had reliable preservation of eGFR with its increase of $1.5 \mathrm{~mL} / \mathrm{min}$ on CIWI, while patients with low functional renal reserve had a drop of eGFR at $1.1 \mathrm{~mL} / \mathrm{min} / \mathrm{m}^{2}$ within 12 months. Patients with low normal serum sodium levels have shown worse results on CIWI. Conclusions: With CKD G1, the CIWI leads to the preservation of the renal function with its increase of GFR per $1 \mathrm{~mL} /$ $\mathrm{min} / \mathrm{m}^{2} /$ per year in comparison with the same water intake. In CKD G2, the CIWI prevents physiological and pathological loss of renal function, and RFR above $50 \%$ aids restoration of eGFR both in CKD G1-2. ECIWIC trial demonstrates benefit of CIWI in patients with CKD 1-2 and preserved RFR.

(C) 2021 The Author(s)

Published by S. Karger AG, Basel

Mariia D. Ivanova

Medicina e Chirurgia, Universita Milano-Bicocca

Via Alfred Nobel

IT-20854 Vedano al Lambro MB (Italy)

mesangium88@gmail.com 


\section{"Early Coaching to Increase Water Intake in CKD" ECIWIC 1-year trial}

Mariia D.Ivanova1, Anatoliy I.Gozhenko2, Tommy Crestanello3, Dmytro D. Ivanov4 1Milano-Bicocca University, Milan, Italy, 2 Ukrainian Scientific Research Institute of Transport, Odesa, Ukraine; $3 ; 4$ Shupyk National Medical Academy of Postgraduate Education, Kiev, Ukraine
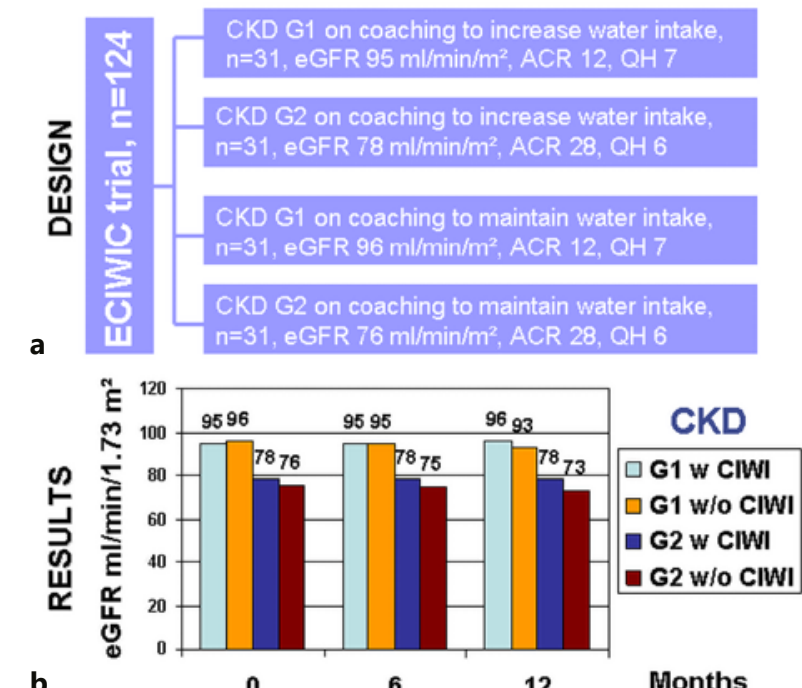

Normal kidney function
eGFR above $100 \mathrm{ml} / \mathrm{min} / \mathrm{m}^{2}$

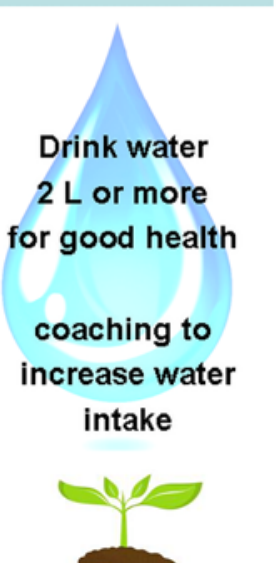

eGFR less than $100 \mathrm{ml} / \mathrm{min} / \mathrm{m}^{2}$ : perform 1 hour kidney functional water test

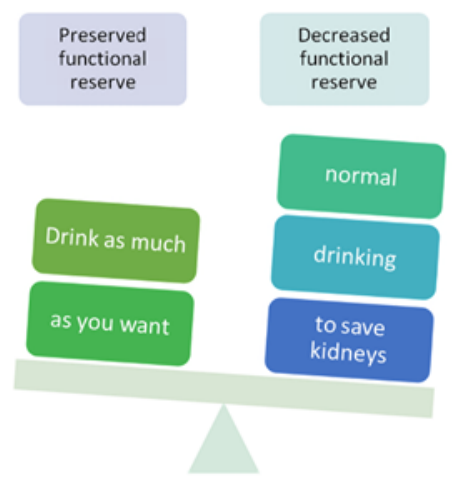

Fig. 1. a The design of the ECIWIC trial indicating 4 groups of patients representing their number, CKD stage, ACR, and patientreported overall $\mathrm{QH}$ ranged from 0 (worst possible) to 10 (best possible). $\mathbf{b}$ The results of ECIWIC trial indicating eGFR change in 4 group of patients within 6 and 12 months from the baseline. The reduction of ACR does not depend on the eGFR but strongly correlates with RFR (CC 0.81). Patient-reported overall QH nonsignificantly has been higher in CIWI groups. c Final recommendations are summarized. ECIWIC, Early Coaching to Increase Water Intake in CKD; eGFR, estimated glomerular filtration rate; ACR, albumin/Cr ratio; $\mathrm{QH}$, quality of health.

\section{Statement of Ethics}

All patients have given their written informed consent. The study protocol was approved by the institute's committee on human research.

\section{Conflict of Interest Statement}

Mariia Ivanova received travel expenses, accommodation, and registration fee from Danone Research to attend the 2019 Hydration for Health Scientific Conference.

\section{References}

1 Clark WF, Sontrop JM, Huang SH, Gallo K, Moist L, House AA, et al. Effect of coaching to increase water intake on kidney function decline in adults with chronic kidney disease: the CKD WIT randomized clinical trial. JAMA. 2018 May 8;319(18):1870-9.
2 Ivanov DD. Renin-angiotensin system blockers and renal functional reserve. Is there a limit of renoprotection? Kidneys. 2015;5(4.14): $12-5$.

3 Ivanov DD, Gozhenko AI, Savytska LM. Individualization of renoprotection in dependence from estimated glomerular filtration rate and renal functional reserve. Nephrology. 2019;23(1):9-14. Russian. 